\title{
Changes in the Intracellular Concentration of Acetyl-CoA and Malonyl-CoA in Relation to the Carbon and Energy Metabolism of Escherichia coli K12
}

\author{
By YOSHICHIKA TAKAMURA* AND GORO NOMURA \\ Department of Agricultural Chemistry, Faculty of Agriculture, Ibaraki University, \\ Ami-machi, Ibaraki-ken 300-03, Japan
}

(Received 1 March 1988; revised 19 April 1988)

\begin{abstract}
Intracellular concentrations of acetyl-CoA and malonyl-CoA in Escherichia coli $\mathrm{K} 12$ were determined by a malonyl-CoA : acetyl-CoA cycling technique. Under aerobic growth conditions with glucose the acetyl-CoA and malonyl-CoA concentrations varied over a range of $0.05-$ $1.5 \mathrm{nmol}(\mathrm{mg} \text { dry } \mathrm{wt})^{-1}(20-600 \mu \mathrm{M})$ and $0.01-0.23 \mathrm{nmol}(\mathrm{mg} \text { dry wt })^{-1}(4-90 \mu \mathrm{M})$, respectively. The intracellular concentration of acetyl-CoA was highest in exponentially growing cells and it fell rapidly to less than $5 \%$ of the maximum level when the organism entered stationary phase after exhaustion of glucose. A linear relationship was observed between the intracellular concentration of total acyl-CoA and the logarithm of the concentration of glucose in the medium. Consequently, the acetyl-CoA/malonyl-CoA ratios also varied drastically, in a range of $0 \cdot 6-41 \cdot 7$, under different conditions. Of several carbon sources tested, glucose was the most effective for promoting the synthesis of cellular acetyl-CoA. For cells grown on glycerol or acetate the maximum concentrations of total acyl-CoA were significantly lower. In cells incubated with citrate (not used as a carbon source by $E$. coli), the level was consistent with that in cells starved for exogenous carbon sources.
\end{abstract}

\section{INTRODUCTION}

Recently, we established a new micromethod for the measurement of acetyl-CoA and malonyl-CoA using malonate decarboxylase (named 'malonyl-CoA:acetyl-CoA cycling') (Takamura et al., 1985). This method is both simple and very sensitive, permitting detection of $10 \mathrm{pmol}$ of acetyl-CoA and malonyl-CoA, and a large number of samples can be assayed in routine experiments using a spectrophotometer.

In vitro experimentation has revealed that acetyl-CoA occupies a central role in the regulation of glycolysis, gluconeogenesis, the tricarboxylic acid cycle and fatty acid synthesis. However, few measurements of the intracellular concentration of the acyl thioesters have been reported, except for recent papers by Bockner \& Ames (1982), Jackowski \& Rock (1986) and Vallari et al. (1987). The procedures used in these studies for determination of CoA-thioesters are complicated and insufficiently sensitive to define rapid changes of intracellular acyl-CoAs. Our method is sufficiently sensitive to detect such changes and the measurement can be done with a small sample of approximately $1 \mathrm{mg}$ dry wt of bacteria (Nomura et al., 1988). In the present work we measured intracellular concentrations of acetyl-CoA and malonyl-CoA of Escherichia coli $\mathrm{K} 12$ cells under carbon source excess as well as carbon source limiting conditions.

\section{METHODS}

Bacterial strain and culture conditions. E. coli $\mathrm{K} 12$ was grown in the synthetic medium used by Chapman et al. (1971) for the study of adenylate energy charge in $E$. coli. This medium contained: $5 \mathrm{~g} \mathrm{KH}_{2} \mathrm{PO}_{4}, 13 \mathrm{~g} \mathrm{~K}_{2} \mathrm{HPO}_{4}$, $0.2 \mathrm{~g} \mathrm{MgCl}_{2}, 2 \mathrm{~g}\left(\mathrm{NH}_{4}\right)_{2} \mathrm{SO}_{4}$ and $5 \mathrm{~g}$ glucose $(28 \mathrm{~mm})$ in 1 litre of distilled water, $\mathrm{pH} 7 \cdot 0$. Cultivation was at $30^{\circ} \mathrm{C}$ in $500 \mathrm{ml}$ shaking flasks containing $100 \mathrm{ml}$ medium. Growth was followed by measuring $\mathrm{OD}_{660} . \mathrm{An} \mathrm{OD}_{660}$ of 1.0 corresponded to $9 \times 10^{8}$ cells $\mathrm{ml}^{-1}$. 
Extraction procedure. A sample of the culture broth $(0 \cdot 5-10 \mathrm{ml})$ of $E$. coli $\mathrm{K} 12$ was centrifuged at $12000 \mathrm{~g}$ for $10 \mathrm{~min}$ at $2{ }^{\circ} \mathrm{C}$. Ths step was indispensable to avoid contamination by acetate excreted into the medium by the organism, since the acid interfered seriously with the cycling assay. To the resulting cell pellet, $10 \mathrm{ml}$ ice-cold $0.3 \mathrm{M}$ sulphuric acid was added and the tube was vortexed for $10 \mathrm{~s}$. The tube was then placed in ice-water for $30 \mathrm{~min}$ to complete liberation of the acyl-CoAs, with periodic vortexing. The cold acid extract obtained by centrifugation was adjusted to $\mathrm{pH} 5-6$ with dilute $\mathrm{NaOH}$. Ten to $200 \mu \mathrm{l}$ of the extract was used for measurement of the acylCoAs by the cycling assay. More than $97 \%$ of authentic acetyl-CoA added to the cell pellet was recovered by this extraction procedure and the extracts could be kept at $0{ }^{\circ} \mathrm{C}$ for at least $2 \mathrm{~d}$ without detectable loss of acyl-CoA (Nomura et al., 1988).

Measurement of acetyl-CoA and malonyl-CoA. The intracellular concentration of CoA-thioesters was determined in duplicate. All results were expressed in $\mathrm{nmol}(\mathrm{mg} \text { dry } \mathrm{wt})^{-1}$ and were the mean of two samples. The intracellular concentrations of acetyl-CoA and malonyl-CoA were determined as described by Takamura et al. (1985).

Enzymes. Malonate decarboxylase was purified from Pseudomonas ovalis IAM 1177, as previously reported (Takamura \& Kitayama, 1981). Acetate kinase [EC 2.7.2.1] and citrate synthase [EC 4.1.3.7] were purchased from BMY Chemicals and Sigma, respectively. All other chemicals were of analytical grade.

Determination of glucose. The residual glucose in the culture broth was determined by the phenol/sulphuric acid method (Dubois et al., 1956).

\section{RESULTS}

Changes in the intracellular concentrations of acetyl-CoA and malonyl-CoA in E. coli K12 grown on glucose/mineral salts medium

There was a remarkable change in the intracellular concentrations of the CoA-thioesters, especially acetyl-CoA, during growth of $E$. coli $\mathrm{K} 12$ on glucose/mineral salts medium (Fig. 1). The acetyl-CoA concentration increased rapidly during the first 4-12 h of exponential growth to a maximal concentration of $1.5 \mathrm{nmol}(\mathrm{mg} \mathrm{dry} \mathrm{wt})^{-1}$. When the cells entered the stationary phase, the concentration fell rapidly to $0.1 \mathrm{nmol}(\mathrm{mg} \text { dry } \mathrm{wt})^{-1}$. Malonyl-CoA showed a maximum concentration of $0.24 \mathrm{nmol}(\mathrm{mg} \text { dry wt })^{-1}$ in the early exponential growth phase and it fell to $0.03 \mathrm{nmol}(\mathrm{mg} \text { dry } \mathrm{wt})^{-1}$ in the stationary growth phase. The change in intracellular concentrations of acetyl-CoA was closely related to the presence of glucose in the medium. Immediately after the exhaustion of glucose, after $24 \mathrm{~h}$ of cultivation, the intracellular acetyl$\mathrm{CoA}$ concentration fell sharply. Cellular acetyl-CoA/malonyl-CoA ratios also varied drastically, from 0.6 in cells harvested in early exponential growth to 41.7 in cells harvested in the stationary phase.

When cells with an original acetyl-CoA concentration of $0.09 \mathrm{nmol}(\mathrm{mg} \text { dry wt })^{-1}$ were placed in fresh medium containing sufficient glucose $(28 \mathrm{~mm})$, the intracellular acetyl-CoA increased 10.3-fold in $30 \mathrm{~min}$ to reach a maximum level of $0.93 \mathrm{nmol}(\mathrm{mg} \text { dry wt })^{-1}$ (Fig. 2). In contrast, malonyl-CoA remained at rather low levels of $0.015-0.032 \mathrm{nmol}(\mathrm{mg} \text { dry wt })^{-1}$. The extent of the change in cellular acyl-CoA observed in the replacement culture was related to the original concentration in the cells transferred and was affected primarily by the presence of glucose. When the cells were placed in a medium from which glucose was omitted, the total acyl-CoA concentration decreased to $0.13 \mathrm{nmol}(\mathrm{mg} \text { dry wt })^{-1}$. When exponentially growing cells $(16 \mathrm{~h}$; Fig. 1) with $1.0 \mathrm{nmol}(\mathrm{mg} \text { dry wt })^{-1}$ of total acyl-CoA were transferred to fresh medium with glucose, the concentration remained unchanged. On the other hand, with cells harvested after $36 \mathrm{~h}$ and $48 \mathrm{~h}$ (Fig. 1) of cultivation, the concentration increased immediately after transfer to fresh medium with glucose to reach an upper level of $1.0 \mathrm{nmol}(\mathrm{mg} \text { dry wt })^{-1}$. Omission of the nitrogen source or addition of chloramphenicol $\left(100 \mu \mathrm{g} \mathrm{ml}^{-1}\right)$ to the glucose medium resulted in failure of the organism to grow. No alterations in the size and composition of the acyl-CoA pool were observed under these conditions, indicating that glucose contributed to controlling the intracellular concentration of acetyl-CoA.

\section{Effect of glucose concentration and nature of carbon sources on the intracellular concentration of total acyl-CoA}

Fig. 3 shows the relation between the concentration of glucose in the medium and the intracellular concentration of total acyl-CoA. Cells with an acyl-CoA concentration of $0.36 \mathrm{nmol}$ (mg dry wt $)^{-1}$ were transferred to media supplied with different concentrations of glucose as 


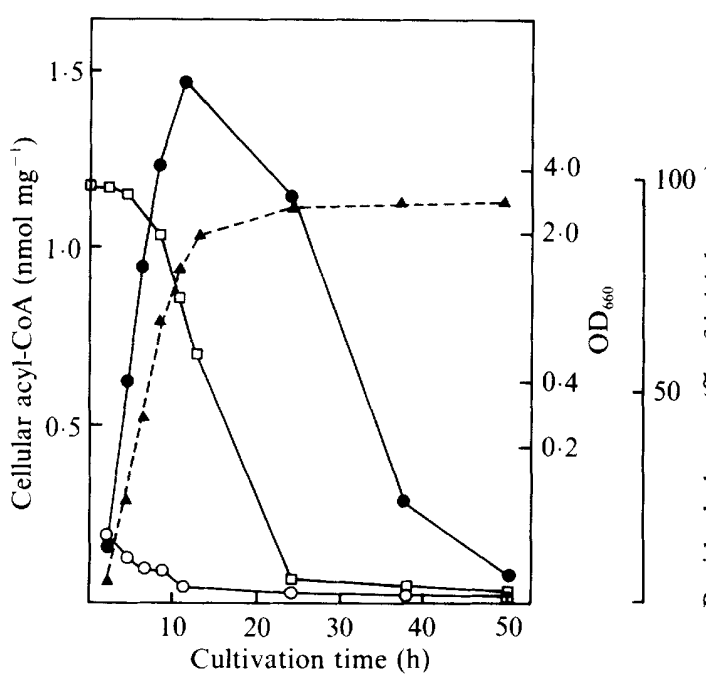

Fig. 1

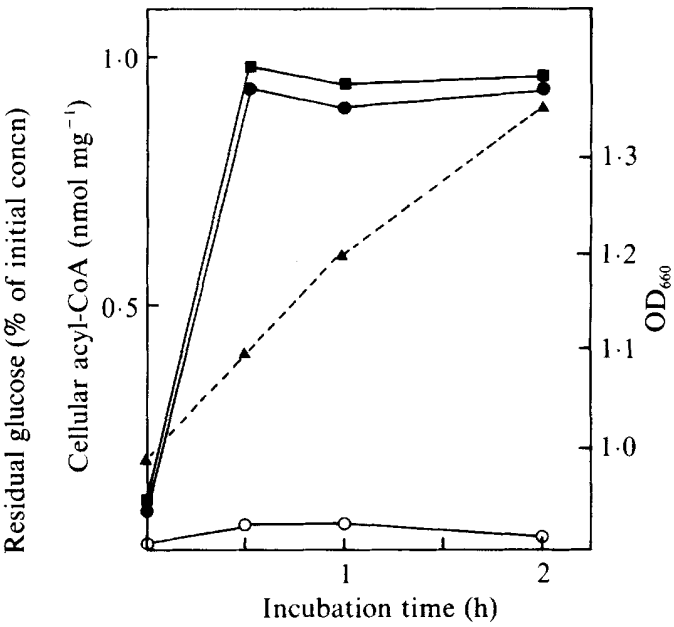

Fig. 2

Fig. 1. Changes in the intracellular concentrations of acetyl-CoA $(O)$ and malonyl-CoA $(O)$ during growth of $E$. coli $\mathrm{K} 12$ on synthetic medium containing $28 \mathrm{~mm}$-glucose. $\square$, Residual glucose in the medium; $\boldsymbol{\Delta}$, growth measured as $\mathrm{OD}_{660}$.

Fig. 2. Changes in the intracellular concentrations of acetyl-CoA and malonyl-CoA of E. coli cells in replacement culture. E. coli $\mathrm{K} 12$ was cultivated for $48 \mathrm{~h}$ in glucose/mineral salts medium and then transferred to fresh medium with $28 \mathrm{~mm}$-glucose to an $\mathrm{OD}_{660}$ of 0.99 . Incubation was carried out at $30{ }^{\circ} \mathrm{C}$, aerobically. $\mathrm{D}$, Intracellular concentration of total acyl-CoA, i.e. the sum of acetyl-CoA and malonyl-CoA; other symbols are as in Fig. 1.

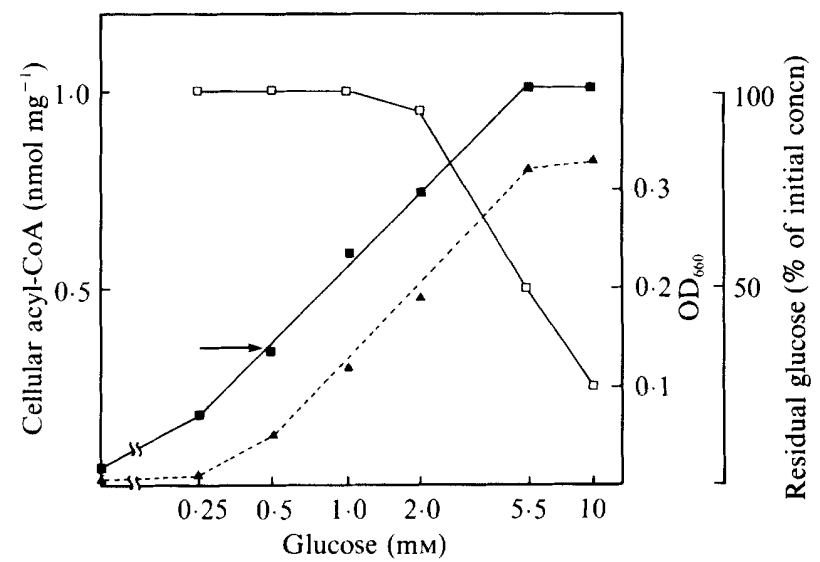

Fig. 3. Relationship between the intracellular concentration of total acyl-CoA and the concentration of glucose in the medium. E. coli K12 cells with an initial concentration of total acyl-CoA of $0.36 \mathrm{nmol}(\mathrm{mg}$ dry weight $)^{-1}$ (this concentration is marked with an arrow on the figure) were transferred to fresh media containing various concentrations of glucose as indicated. Incubation was carried out at $30^{\circ} \mathrm{C}$, aerobically, for $1 \mathrm{~h}$, then the intracellular concentration of total acyl-CoA $(\mathbf{D}), \mathrm{OD}_{660}(\mathbf{\Delta})$ and residual glucose $(\square)$ were measured.

indicated in Fig. 3. After $1 \mathrm{~h}$ incubation with shaking at $30^{\circ} \mathrm{C}$, the intracellular concentration of total acyl-CoA was measured. A linear relationship was obtained between the intracellular concentration of total acyl-CoA and the logarithm of glucose concentration. When the cells were incubated in media containing less than $0.5 \mathrm{~mm}$-glucose, the total acyl-CoA concentration was 
reduced, and in the cells incubated without glucose it fell to the lowest level. On the other hand, at glucose concentrations above $0.5 \mathrm{~mm}$, the acyl-CoA concentration increased, reaching a maximum of $1.0 \mathrm{nmol}(\mathrm{mg} \text { dry wt })^{-1}$ at about $5.5 \mathrm{~mm}$-glucose. Although a significant amount of glucose remained unconsumed when it was supplied at a concentration of $2.0 \mathrm{mM}$, the cellular total acyl-CoA was not saturated under these conditions, suggesting that the maximum concentration of total acyl-CoA was not necessarily determined by the apparent excess of glucose in the medium.

Various carbon sources other than glucose, each at a concentration of $28 \mathrm{~mm}$, were examined for their effect on the cellular total acyl-CoA. All except citrate served to increase the intracellular level of total acyl-CoA. Among the carbon sources tested, glucose was the most effective in increasing the intracellular acyl-CoA concentration, giving a value of $1.2 \mathrm{nmol}(\mathrm{mg}$ dry wt) ${ }^{-1}$ after 30 min of incubation. Although lactose produced a similar concentration of total acyl-CoA after $2 \mathrm{~h}$ of incubation, the total acyl-CoA concentration during the first 30 min was less than $40 \%$ of that in cells grown on glucose. This lag may have been due to the induction of the lactose operon in $E$. coli K12. In cells grown on glycerol or acetate, the maximum concentrations of total acyl-CoA were significantly reduced: in cells grown on glycerol the concentration was about half of that in cells grown on glucose. In cells incubated with citrate, which cannot be used as a carbon source by $E$. coli, the intracellular concentration of total acylCoA decreased from an original value of $0.09 \mathrm{nmol}(\mathrm{mg} \text { dry wt })^{-1}$ to $0.04 \mathrm{nmol}(\mathrm{mg} \text { dry wt })^{-1}$ in $2 \mathrm{~h}$, a change almost consistent with that observed in cells starved for exogenous carbon sources.

\section{DISCUSSION}

Measurements of cellular nucleotides such as ATP, NAD and NADP have been made by a number of workers, but very little work has been done to define the changes in the intracellular concentrations of CoA-thioesters in response to different cultural conditions. In this study with $E$. coli $\mathrm{K} 12$, dramatic and rapid changes were observed, especially in the intracellular concentrations of acetyl-CoA, and these correlated with the physiological state of the cells. Bockner \& Ames (1982) analysed cellular nucleotides by two-dimensional thin-layer chromatography in ${ }^{32} \mathrm{P}_{\mathrm{i}}$-labelled cells of Salmonella typhimurium grown on glucose and showed that the approximate intracellular concentrations of acetyl-CoA and malonyl-CoA were $231 \mu \mathrm{M}$ and $15 \mu \mathrm{M}$, respectively. Jackowski \& Rock (1986) reported that acetyl-CoA was the dominant component $(79.8 \%$ ) of the CoA pool in cells of $E$. coli exponentially growing in glucose/mineral salts medium, with significant concentrations of succinyl-CoA $(5.9 \%)$ and malonyl-CoA $(0.5 \%)$. Vallari et al. (1987) found considerable differences in the size and composition of the CoA pool in cells of the same strain grown on different carbon sources, ranging from 20 to $323 \mu \mathrm{M}$ for acetyl-CoA and from 2 to $35 \mu \mathrm{M}$ for malonyl-CoA. In the present work we demonstrated that the intracellular concentrations of acetyl-CoA and malonyl-CoA changed in the range 0.05 $1.5 \mathrm{nmol}(\mathrm{mg} \text { dry wt})^{-1}$ and $0.01-0.23 \mathrm{nmol}(\mathrm{mg} \mathrm{dry} \mathrm{wt})^{-1}$, respectively. On the assumption that acyl-CoAs are uniformly distributed within the cell, and that the internal water volume of $E$. coli is $2.7 \mathrm{ml}$ (g dry wt) ${ }^{-1}$ (Swedes et al., 1975), it can be calculated that the intracellular concentration of acetyl-CoA changed in the range $20-600 \mu \mathrm{M}$, while that of malonyl-CoA varied between 4 and $90 \mu \mathrm{M}$.

A number of workers have reported that the activities of pyruvate dehydrogenase (Hansen $\&$ Henning, 1966; Schwartz et al., 1968; Shen et al., 1968), pyruvate carboxylase (Cazzulo \& Stoppanni, 1967; Cooper \& Benedict, 1968), phosphoenolpyruvate carboxylase (Canovas \& Kornberg, 1965; Sanwal \& Maeba, 1966; Utter \& Kohlenbrander, 1972), 6-phosphogluconate dehydrogenase (Sugimoto \& Shiio, 1987) and fatty acid synthetase (Kawaguchi et al., 1980; Okuyama et al., 1982) are controlled by acetyl-CoA at concentrations of $13-840 \mu \mathrm{M}$. These in vitro concentrations and ratios described are consistent with the range of the intracellular concentrations of acetyl-CoA and malonyl-CoA reported here, suggesting that a contribution of the two CoA thioesters to in vivo regulation is quite probable.

It is noteworthy that the maximum concentration of acetyl-CoA varied in response to the nature of the carbon source and that it decreased in the order glucose $>$ lactose $>$ acetate $>$ 
glycerol. Measurement of the size and composition of the CoA-thioester pool may therefore provide a valuable technique to identify in vivo physiological states of cells and to reveal in vivo regulation related to carbon and energy metabolism.

The authors thank Professor Masami Soejima and Associate Professor Takeji Masaki in our Department for valuable discussion.

\section{REFERENCES}

BOCKNER, B. R. \& AMES, B. N. (1982). Complete analysis of cellular nucleotides by two dimensional thin layer chromatography. Journal of Biological Chemistry 257, 9759-9769.

Canovas, J. K. \& Kornberg, H. L. (1965). Fine control of phosphoenolpyruvate carboxylase activity in Escherichia coli. Biochimica et biophysica acta 96, 169-172.

Cazzulo, J. J. \& Stoppanni, A. O. M. (1967). Purification and properties of pyruvate carboxylase from baker's yeast. Archives of Biochemistry and Biophysics 121, 596-608.

Chapman, A. G., Fall, I. \& Atkinson, D. E. (1971). Adenylate energy charge in Escherichia coli during growth and starvation. Journal of Bacteriology 108, 1072-1086.

COOPER, T. G. \& Benedict, C. R. (1968). Regulation of pyruvate carboxylase by coenzyme $\mathrm{A}$ and acylcoenzyme A thioesters. Biochemistry 7, 3032-3036.

Dubois, M., Gilles, K. A., Hamilton, J. K., Rebers, P. A. \& SMITH, F. (1956). A colorimetric method for determination of sugars. Analytical Chemistry 28, 350-356.

Hansen, R. G. \& Henning, U. (1966). Regulation of pyruvate dehydrogenase activity in, Escherichia coli K-12. Biochimica et biophysica acta 12, 355-358.

JACKowsKI, S. \& RoCK, C. O. (1986). Consequences of reduced intracellular coenzyme A content in Escherichia coli. Journal of Bacteriology 166, 866-871.

Kawaguchi, A., Arai, K., Seyama, Y., Yamakawa, T. \& OKUDA, S. (1980). Substrate control of termination of fatty acid synthesis by fatty acid synthetase from Brevibacterium ammoniagenes. Journal of Biochemistry 88, 303-306.

Nomura, G., Yoshida, Y. \& Takamura, Y. (1988). Measurement of the intracellular concentrations of acetyl-CoA and malonyl-CoA in bacteria and yeasts using acyl-CoA cycling. Agricultural and Biological Chemistry 52, 843-844.

Okuyama, H., Saitoh, M. \& Hiramatsu, R. (1982). Fatty acid synthetase system in the regulation of membrane lipid synthesis in Escherichia coli after shift in temperature. Journal of Biological Chemistry 257, 4812-4817.

SanWaL, B. D. \& MAEBA, P. (1966). Regulation of the activity of phosphoenolpyruvate carboxylase by fructose diphosphate. Biochimica et biophysica acta 22, 194-199.

Schwartz, E. R., OLd, L. O. \& ReEd, L. J. (1968). Regulatory properties of pyruvate dehydrogenase from Escherichia coli. Biochemical and Biophysical Research Communications 31, 495-500.

Shen, L. C., Fall, L., Walton, G. M. \& Atkinson, D. E. (1968). Interaction between energy charge and metabolic modulation in the regulation of enzymes of amphibolic sequences. Phosphofructokinase and pyruvate dehydrogenase. Biochemistry 7, 4041-4045.

Sugimoto, S. \& SHIIo, I. (1987). Regulation of 6phosphogluconate dehydrogenase in Brevibacterium flavum. Agricultural and Biological Chemistry 51, 1257-1263.

Swedes, J. S., Sedo, R. T. \& Atkinson, D. E. (1975). Relation of growth and protein synthesis to the adenylate energy charge in adenine-requiring mutant of Escherichia coli. Journal of Biological Chemistry 250, 6930-6938.

Takamura, Y. \& Kitayama, Y. (1981). Purification and some properties of malonate decarboxylase. Biochemistry International 3, 483-491.

Takamura, Y., Kitayama, Y., ARakawa, A., YamanaKa, S., Tosaki, M. \& Ogawa, Y. (1985). MalonylCoA : acetyl-CoA cycling. A new micromethod for determination of acyl-CoAs with malonate decarboxylase. Biochimica et biophysica acta 83, 1-7.

UTTER, M. F. \& KOHLENBRANDER, M. (1972). Formation of oxaloacetate by $\mathrm{CO}_{2}$ fixation on phosphoenolpyruvate. In The Enzymes, vol. 6, pp. 117-168. Edited by P. D. Boyer. New York: Academic Press.

VALlARI, D. S., JACKowsKi, S. \& RoCK, C. O. (1987). Regulation of pantothenate kinase by coenzyme A and its thioesters. Journal of Biological Chemistry 262, $2468-2471$. 